\title{
Advances in Cancer Gene Therapy
}

Ming Yu $^{*}$, M.D.

* To whom correspondence should be addressed: Department of Cell Biology, Georgetown University, Medical Center, 3900 Reservoir Rd., N.W. Washington DC, 20007 USA

\section{INTRODUCTION}

Recent developments in molecular and cell biology have not only contributed to our understanding of the molecular basis of disease but have also provided potential technologies for manipulation of genes in vivo. With the knowledge that many human diseases are caused by inherited or acquired abnormalities in gene expression and regulation, gene therapy was developed as a means of reversing the pathogenic process at its source: the hope was that functional genes, inserted into cells, would be able to augment cell function and yield the required gene product, thus compensating for genetic defects and curing disease. Approved and initiated in September 1990, the first gene therapy protocol, designed to treat adenosine deaminase (ADA) deficiency (1), realized some of these early hopes. Ex vivo transfer of the ADA gene into peripheral blood lymphocytes and bone marrow progenitor cells of patients with severe combined immunodeficiency associated with adenosine deaminase deficiency (ADA-SCID) resulted in normalization of the immune repertoire and restoration of cellular and humoral immunity in the treated patients $(2,3)$.

The success of gene therapy for treatment of ADA-SCID, while an important accomplishment in itself, also had wide-ranging implications for the treatment of other diseases. Researchers quickly seized upon the potential for gene therapy in the treatment of cancer, a disease that has long been known to result from abnormal gene expression and regulation. While chemotherapy and radiotherapy have prolonged survival and, in some cases, provided cures, their disadvantages are well-known. Designed to target proliferating cells rather than cancer cells specifically, cancer chemotherapy is plagued by its lack of selectivity: significant and life-threatening side effects limit allowable dose and, thereby, therapeutic effect, resulting in high recurrence rates for most solid tumors. Unlike conventional therapies, gene therapy for cancer promises specific targeting of cancer cells and, hence, fewer toxic effects and greater potential for cure.

\section{TRANSGENIC IMMUNOTHERAPY}

Although tumor cells present tumor associated antigens (TAA) (4-7), tumors are nonetheless predominantly poor immunogens $(8,9)$. Immunologists have long been attempting to induce anti-tumor immune responses for cancer therapy, either by increasing tumor cell immunogenicity or enhancing the effector cell anti-tumor immune responses. Recently, intense interest has developed in the introduction of genes into tumor or effector cells with the aim of augmenting cellular function at the tumor site, helping the body to overcome immune tolerance, and eliciting a local or systemic anti-tumor immune response (10). The major approaches in transgenic immunotherapy include: i) tumor vaccines, ii) tumor infiltrating lymphocyte (TIL) adoptive immunotherapy, iii) lymphocyte tumor homing, and iv) antibody-dependent cell-mediated cytotoxicity 
(ADCC).

\section{Tumor vaccine}

Recombinant tumor vaccines are generated by transfecting genes into tumor cells to render the tumor more immunogenic. The underlying hypothesis is that the expression of one or more of the transgenic products in some of the tumor cells may promote recognition by and activation of cytotoxic T lymphocytes (CTLs). This technique may not only elicit an immune response to the primary tumor but also generate a systemic antitumor response with immune memory. The steps involved in recombinant tumor vaccination include: i) primary culture of the tumor cells from the surgical material; ii) ex vivo transduction of the cells with the chosen gene; iii) UV irradiation the genetically modified cells; and iv) reinjection of these cells into the patient's body. In accordance with the mechanism of cytotoxic immune response, three different types of genes have been used for tumor vaccination.

Based on the concept of associated recognition, one strategy in tumor vaccines involves the use of genes encoding proteins foreign to the host-allogenization, known as xenogenization. Xenogenization stems from the idea that, while minor cell surface differences are insufficient for induction of an immune response, additional antigen may induce immune recognition of the original TAA and elicit systemic protection against tumor cells. Acquired through the cloning of genes and the identification of tumor antigens and tumor rejection antigens, our understanding of the mechanisms of antigen presentation and immune recognition has made active specific immunotherapy a potential treatment for certain cancers $(11,12)$.

Genes coding for MHC (10,13), several virus antigens $(14,15)$, carcinoembryonic antigens (CEA) (16), tumor antigens, tumor rejection antigens, several normal tissue antigens (17), and p53 (18) have been used to introduce a target for cancer rejection. The use of tumor antigen polymorphic epithelial mucin (PEM) (12) CEA (16), and p53 (18) for cancer vaccines has been reported to generate good anti-tumor responses in animal models. TA-HPV, a recombinant human papilloma virus involving types E16 and E18, has been reported to provoke HPV-specific antibody response (15). Melanocyte differentiation antigens restricted by HLA-A2 and HLA-A24, which cause vitiligo, have been implicated in antigen-associated cancer regression of melanoma (17). CEA demonstrates specific T-cell responses against CEA-positive cancer cells (16) in patients. Several clinical trials using tumor antigens and tumor rejection antigens are currently in progress $(11,12)$.

Another set of genes used in tumor vaccines includes genes encoding accessory proteins for costimulation of T cell activation, such as B7, comprised of A family of costimulatory molecules expressed on the surface of antigen presenting cells (APCs), such as monocytes, B7 is the natural ligand for the costimulatory molecules CD28 and CTLA-4 on T lymphocytes. The T cell costimulatory ligand interactions between B7 and CD28 during the antigen recognition process generate a second signal required for $\mathrm{CD}^{+} \mathrm{CTL}$-dependent antigen priming $(19,20)$ and primary T lymphocyte activation (21-23). Without the signal, CTLs, which are known to play the most important role in anti-tumor immunity, become anergic. Studies on naive mice showed that B7 molecules mediated MHC-antigen-induced anti-tumor immunity (24). Expression of B7 accessory protein was found to be lacking in some tumor cells (25-28) and to be decreased in some APCs presenting tumor epitopes (29). Furthermore, it has been suggested that oncoprotein may alter the binding of epitope by B7 peptide (30). These B7 deficiencies in the cancer patient have been postulated to be causal in immune tolerance. On the other hand, included over-expression of B7 in tumor cells may permit direct priming of the CTL, bypassing the APC.

Although the precise mechanism remains unknown, B7-based tumor vaccines have resulted in tumor rejection and systemic anti-tumor immunity in many animal model systems (24,31-34). Animal experiments have shown that injection of B7-transfected tumor cells led the normal animal to reject the tumor cells (31) and resist subsequent challenge $(31,32)$. It has also been observed that the injection of B7-transfected tumor 
cells may elicit systemic anti-tumor responses, including: rejection of the B7-negative parental (31) or wildtype (24) tumor; tumor regression $(31)$ and eradication $(31,32)$ from animals bearing the parental tumor; decreased lung metastasis in the intravenous injection model (33), and prevention of spontaneous lung metastasis in animals subcutaneously inoculated with B7-negative parental tumor cell, leading to prolonged survival (33). B7-induced anti-tumor immunity has been demonstrated to be tumor-specific $(33,34)$ and longlasting, even after single injection (32). Antibody-blocking studies have shown that these effects are CTLdependent (33) and are mediated by B7 $(24,32,34)$ and CD28 (32).

More detailed studies have shown that B7 is required for primary $\mathrm{T}$ cell activation and priming (19), but that once the CTL has been primed, memory T lymphocytes do not require B7 for their functioning $(20,23,24)$. Therefore, the injection of B7-transfected tumor cells can elicit systemic immune responses against the B7negative parental tumor. Thus, the B7-based tumor vaccine has the distinct advantage of eliciting systemic anti-tumor response against both parental and metastatic tumors.

B7 transduction has been attempted in a variety of cancers. Transducing melanoma cells with the B7 gene induces potent systemic anti-tumor response in both human melanoma patients (13) and animal models $(25,35,36)$. Seven clinical trials using B7-transfected tumor cells for different types of tumors are in progress (Table 1) (38-46). Fifty percent or greater reduction in tumor size has been observed in melanoma patients with large tumor burdens receiving intra-tumoral injection of B7 alloantigen cDNA (90). This observation is encouraging, and suggests that B7-based tumor vaccines may represent a feasible approach for cancer therapy, especially for patients with metastatic tumor.

Several reports suggest, however, that B7 alone is not sufficient to elicit a tumor rejection response $(91,92)$. Numerous cytokines interacting with B7 may be required for B7 function (91-93). It has been suggested that IL-10 and IFN-gamma inhibit B7 expression (94), whereas GM-CSF and IL-1b increase B7 expression (95). IL-12 may cooperate with B7 (96). A better understanding of these interactions will be crucial in directing B7-based tumor vaccine development.

Genes encoding cytokines, the key modulators of host immune and inflammatory responses, have been a third area of interest in tumor vaccine technology. The expression of cytokine genes by tumor cells generates a high level of cytokines in paracrine fashion at the tumor site, inducing powerful local cytokine effects without significant systemic toxicity. This approach is aimed at direct activation of CTLs to recognize the tumor cells, thus aiding the host immune system to induce specific anti-tumor immune responses and systemic protective effects.

Several cytokines have been explored in recent years, interleukin-2 (IL-2) having received the most attention. Secreted by activated $\mathrm{CD} 4^{+}$Th cells, IL- 2 activates $\mathrm{CD} 8^{+} \mathrm{CTL}$ cells, responsible for mounting an anti-tumor response. Bypassing the function of the $\mathrm{CD}^{+}{ }^{+}$Th cell, which may be defective in tumor patients, genetically modified tumor cells secreting IL-2 at the tumor site provide the second signal required to activate tumor-specific CTLs directly. Increased IL-2 may also activate NK cells and lymphokine-activated killer cells (LAKs). Animal experiments have shown that injection of IL-2-transduced tumor cells increases specific anti-tumor activity, generates systemic responses to the parental tumor, augments the immune response against autologous tumor, and causes rejection of rechallenged tumor cells $(14,97)$. Clinical trials with IL-2transduced tumor cells are ongoing $(28,52-54)$. To simplify the process of tumor vaccination, efforts have also focused on generating allogeneic IL-2-transduced cell lines against autologous tumor.

Pre-clinical studies have shown that both B7 $(25,36,98)$ and IL-2 (99) produce the most consistent anti-tumor responses. They can also elicit systemic protection and generate immune memory against the parental tumor. However, the anti-tumor effect of other tested cytokines is less clear. Dranoff reported that among the ten tested murine cytokines, GM-CSF, when its gene was used to transduce B16 melanoma cells, produces the 
most potent, long-lasting, and specific anti-tumor immunity in syngeneic mice (100). McGary found that highly metastatic $13762 \mathrm{NF}$ rat mammary adenocarcinoma clones demonstrate GM-CSF-like activity (101), and Roncaroli reported that the GM-CSF receptor was expressed in metastatic breast carcinomas but not in the corresponding primary tumors (102). These apparently conflicting results may be due to intrinsic differences in model systems and/or tumor types. Therefore, careful characterization of each study system and tumor, as well as judicious choice of an appropriate transgene, are likely to be crucial for success of tumor vaccine.

\section{Tumor Infiltrating Lymphocyte (TIL) Adoptive Immunotherapy}

TILs, comprised mainly of CTLs and macrophages (103), are lymphocytes derived from a surgically-excised tumor. The lymphocytes can proliferate to a large number when they grow in the presence of IL-2 and can then be used for systemic adoptive immunotherapy when they are returned to patients (104). Administration

of ${ }^{111}$ In-labeled TILs has demonstrated localization to tumor sites in some patients (104). One third of patients with advanced melanoma treated with TIL reinjection plus high-dose IL-2 showed objective response to this treatment (105). TILs labeled with neomycin phosphotransferase (NeoR) were detected in the circulation up to 189 days, and in tumor deposits up to 64 days, after infusion (104). Therefore, TILs may be a useful tool for targeting cancer.

Based on these observations, strategies were designed to transfect TILs with genes encoding TNF or IL-2 in order to deliver these cytokines to the tumor site.

Pre-clinical studies in mice have shown that

IL-2-transduced TILs produced significant reduction B16F10 lung metastasis, and led to longer survival time in an intracerebral tumor model (106). The use of

TNF-alpha in adoptive immunotherapy has also proved promising. Systemic TNF-alpha treatment with a minimum dose of $400 \mathrm{mg}$ TNF-alpha/kg produced tumor regression in a murine model (104). However, the maximum tolerated dose in humans is $8 \mathrm{mg} / \mathrm{kg}$. Human studies have shown that one out of ten melanoma patients treated with

TNF-alpha adoptive immunotherapy experienced an objective response (107). Unfortunately, the toxicity of TNF-alpha has impeded its use in human cancer therapy. Although TIL adoptive immunotherapy alone may not provide sufficiently high specificity and response rates, the combination of adoptive immunotherapy with tumor vaccine for tumor therapy may yield more encouraging results (107).

\section{Lymphocyte tumor homing}

Another approach in transgenic immunotherapy raises the possibility of utilizing lymphocytes, with their potential tumor-homing properties, as effector cells directed against the tumor. The technique involves transducing a chimeric T cell receptor gene into an effector cell, such as a CTL. The chimeric gene may be constructed by either one of two techniques: i) by joining the artificially constructed single chain of an antitumor antibody (variable regions) to $\mathrm{T}$ cell receptor signaling chains (104), or ii) by substituting the $\mathrm{T}$ cell receptor variable region with the variable regions of the anti-tumor immunoglobulin (Ig) light and heavy chains (108). The recombinant $\mathrm{T}$ cell receptor thus reassigns a new anti-tumor specificity to the $\mathrm{T}$ cells, in the same fashion as has been shown with bispecific antibodies. The expectation is that the chimeric receptor appearing on the T cell surface will genetically redirect the effector cells to attack tumor cells specifically, and will result in both activation of effector cells and killing of target cells not restricted by MHC (108).

Pre-clinical studies demonstrated that, when transduced by a construct consisting of anti-TNP (trinitrophenyl) and anti-ovarian monoclonal antibody $(\mathrm{mAb})$ variable regions, TILs were redirected to lyse TNP-labeled Daudi cells and ovarian carcinoma cells, respectively. This lysis was specific, and the redirected TILs were capable of secreting GM-CSF following stimulation by the appropriate antigen (104). These chimeric TcR$\mathrm{mAb}$ gene-modified lymphocytes potentially offer the advantage of producing a more homogeneous 
population of effectors that contains a high percentage of tumor-reactive killer cells.

However, several significant challenges remain. For instance, this strategy requires development of a singlestranded $\mathrm{mAb}$ or the isolation of a specific Ig gene, both arduous and time-consuming tasks. Although these techniques may not be practical for treating the individual patient, they may be useful for targeting tumors expressing known tumor associated antigens or certain viral antigens. Furthermore, it remains to be demonstrated whether the transduction of a foreign gene into the TIL might have some effect on TIL function.

\section{Antibody-dependent cell-mediated cytotoxicity}

Based on the concept that the effector functions of antibody molecules may involve unique immunomodulating properties, the use of ADCC as a novel strategy in transgenic immunotherapy involves transfection of tumor cells with $\mathrm{mAb}$ genes to initiate an anti-tumor cytotoxic reaction. One report describes human colon carcinoma cells transfected with the light- and heavy-chain genes of a mAb reactive with a membrane antigen found on the majority of human colon carcinomas (108). Transduced tumor cells, which constitutively express tumor antigen on their surface, produce antibody reactive with the antigen both on the cell surface and in the medium. This antibody production enhanced monocyte-mediated cytotoxicity and both modified and non-modified tumor cell sensitivity to NK cells in vitro, and dramatically decreased the tumor volume in vivo. As applied to transgenic immunotherapy, ADCC provides an autocrine and paracrine mechanism for further activation of FcR-bearing killer cells, such as macrophages and NK cells, to destroy targeted tumor cells. By interacting with cell surface tumor-associated antigens, a locally-produced antibody that only exposes tumor cells to the cytotoxic action of these effector cells, but may also help to induce other anti-tumor activity by facilitating antigen presentation and specific CTL response. Although ADCC could complement or extend current extensive efforts involving other genes and cytokines, further investigation is required to determine whether ADCC is capable of targeting metastatic tumor cells.

\section{SUICIDE STRATEGIES}

The suicide strategy involves introduction of a gene encoding a non-mammalian enzyme into tumor cells, followed by systemic administration of high doses of a non-toxic prodrug. The enzyme selected for this purpose catalyzes a reaction that does not occur in mammalian cells, through which the non-toxic prodrug is selectively metabolized to its toxic form. Restriction of expression of the enzyme transgene to the tumor theoretically allows conversion of the prodrug to its toxic form to occur only at the site of the tumor (ig. 1). In this way, a high concentration of chemotherapeutic drug is limited to the tumor site and kills tumor cells selectively, without residual systemic toxicity. Early experiments in this area utilized a viral enzyme, resulting in the use of Virus-Directed Enzyme/Prodrug Therapy (VDEPT) as an alternative terminology for such suicide strategies.

The use of a non-mammalian enzyme to convert a nontoxic prodrug to a toxic anabolite was originally documented in early reports illustrating the mechanisms of action of certain antiviral agents. The principle was first adopted in oncology by Moolten in 1987 (109), when he created genetic mosaics that were artificially induced with genes altering sensitivity to therapeutic agents (109). Moolten used ganciclovir (GCV), a substrate of herpes simplex virus thymidine kinase (HSV-TK), to treat Abelson leukemia virusinduced lymphoma in HSV-TK transgenic mice. This treatment led to tumor regression and extended survival in the animals for more than 100 days (110). Since then, systems using varicella-zoster virus thymidine kinase (VZV TK) (111) and Escherichia coli cytosine deaminase (CD) $(112,113)$ have also been developed (Table 2).

The goal of the VDEPT approach is to engineer sensitivity to tumors cells through DNA recombination and gene transferring techniques (111-113). Tissue-specific gene transfer and regulation of expression are crucial 
to creating artificial transcription differences between normal and neoplastic cells. Different levels of control may be possible, through: local injection of the construct or genetically engineered cells (114), tumor specific receptor-ligand interactions, and the introduction of tumor-marker gene promoters into the construct (Table 3). Through control of the tumor-specific promoter, the transgene may be expressed in tumor cells but not in normal cells (112). Pre-clinical studies using HSV-TK $(110,114,117)$ controlled by CEA showed considerable tumor regression $(110,112,114,117)$ and extended survival of animals $(110,112,114)$. Since the VDEPT strategy introduces a gene that will generate toxic agents, the safest approach may involve control by both cell-specific targeting and tumor-specific gene expression.

The advantage and practicality of the suicide strategy lie in the ability of one transfected tumor cell to cause the death of surrounding wild-type tumor cells. A variety of animal experiments have shown inhibition of tumor growth (118), decrease in tumor volume $(119,120)$, tumor regression $(110,112,114,117,121,122)$, decrease in tumor index (123), extended survival (123-127), and eradication of tumors $(123,124,127,128)$ in a wide range of tumor models. Several Phase I clinical trials are currently in progress $(38,58,70-80)$ and show considerable promise.

Further studies have found that HSV-TK-positive cells exposed to GCV were lethal to HSV-TK-negative cells both in vitro and in vivo $(129,130-136)$. This effect was found even when HSV-TK-positive cells represented as few as $10 \%$ of the tumor cells (129) or $4 \%$ of the cytosine deaminase (CD)-carrying cells (137). Termed the "bystander effect," the phenomenon depends on the presence of gap junctions and direct contact between HSV-TK-positive and -negative cells $(129,134,138)$. Phagocytosis of the apoptotic vesicles generated from the dying gene-modified cells (129), metabolic cooperation between the gene-modified and non-modified cells via gap junctions $(133,138)$, and elicitation of systemic anti-tumor immunity $(136,139)$ have all been implicated. Because of the bystander effect, transfection of only some of the tumor cells will cause killing of untransfected tumor cells in situ as well as some of the tumor cells distal to the primary injection site. Thus, the "bystander effect" overcomes, to some extent, the technical difficulty involved in obtaining high transfection efficiency and enhances the potential of VDEPT for cancer therapy.

\section{GENETIC SUPPRESSION OF TUMOR PHENOTYPE}

Because most or all human cancers result from the expression and/or failure of expression of specific genes-i.e., loss of tumor-suppressor genes or expression of oncogenes--the restoration of tumor suppressor function or suppression of oncogene function through gene transfer and expression may alter the phenotype of tumor cells (140-153). This feature of tumor cells provides the opportunity for cancer therapy by correction of a genetic lesion, made possible by modern techniques.

Approaches to correcting tumorigenic genetic lesions largely depend on whether the determinant genetic changes result from gain-of-function or loss-of-function mutations, and the number of genes to be targeted should be strictly limited. Usually, the targets are oncogenes or tumor suppressor genes.

\section{Targeting of oncogenes}

Proto-oncogenes participate in critical cell functions, including signal transduction and transcription. A single mutant allele or oncogene is sufficient for malignant transformation. Transforming oncogenes arise by virtue of dominantly-acting, also known as dominant-negative, mutations. Turning off such functions, either by correcting the mutant genetic sequence itself or interfering with its expression--are likely to be necessary to achieve genetic reversion of the tumorigenic phenotype. Genetic tools are not currently available for efficient correction of dominantly-acting mutations. However, interference with genetic expression might be accomplished with high level expression of antisense sequences or ribozymes targeted specifically to the oncogenic messenger RNA $(142,143)$. Antisense oligodeoxynucleotides against c-myb, c-muc, H-c-ras, $b c r / a b l$, PCNA, CDC2, (142) and EGF-related growth factor (144) have been shown to inhibit cell growth 
and proliferation in a variety of cell types in vitro; some have been shown to induce apoptosis in T cell hybridomas (142). An anti-fos ribozyme completely reversed the multi-drug-resistant phenotype of human ovarian carcinomas (143), and an anti-ras ribozyme altered a human melanoma phenotype (146) in vitro. In vivo study has shown that antisense c-fos vector transfection results in inhibition of tumor growth and invasiveness, inhibition of production of c-fos protein, induction of cell differentiation, and prolonged survival time (154). Ex vivo antisense c-fos, k-ras, and bcr-abl vector transfections are currently in clinical trials $(38,84-87)$.

Another approach for targeting oncogenes is to transfect cells with an anti-oncoprotein single-chain antibody gene construct to allow the cells to produce intracellular single-chain antibody, which may inactivate the oncoprotein within the cell. Anti-ErbB-2 single-chain antibody ( $\mathrm{scFv}$ ) has been reported to mediate intracellular retention of $E r b B-2$ by binding to the extracellular domain of newly synthesized $E r b B-2$, preventing its transit through the endoplasmic reticulum to the cell surface. Expression of scFv in $E r b B-2$ transformed NIH 3T3 fibroblasts resulted in functional inactivation of the receptor and complete reversion of transformation (147). Since the artificially generated single-strand antibody may function simply by binding the target protein in a dynamic manner, further study is needed to clarify the fate of the targeted protein.

\section{Reconstitution of tumor suppressor genes}

Expression of tumor-suppressor genes results in dominance of the normal phenotype over the tumor phenotype due to the apparent supremacy of tumor-suppressor genes in regulating growth and replication properties of cells (155). The restoration of a state of functional heterozygosity for the mutant gene might, under ideal conditions, be expected to result in a reversion of the neoplastic cellular phenotype to normal. The candidate genes for this purpose clearly must be those playing a key role in tumor suppression, such as Retinoblastoma gene $(\mathrm{Rb})$ and $\mathrm{p} 53$.

The first gene identified as having tumor-suppression function, Rb codes for a nuclear phosphoprotein, $\mathrm{p} 105 \mathrm{Rb}$, that is crucial in the differentiation and replication of undifferentiated cells. Homozygous loss of wild-type $\mathrm{Rb}$ gene causes retinoblastoma and osteosarcoma. Loss of $\mathrm{Rb}$ function is also associated with small cell lung carcinoma, bladder and prostate carcinoma, and some breast cancers. Introduction of a normal allele of the $\mathrm{Rb}$ gene into human retinoblastoma and osteosarcoma cells results in reversion of cell growth and morphology to normal and suppresses tumorigenicity of these cells in nude mice (148).

p53 is a multi-functional nuclear phosphoprotein that plays a central role in modulating gene transcription, regulating the cell cycle, activating apoptosis, maintaining genomic stability, and responding to genetic insults. The "guardian of the genome," it acts principally as a Rumor-suppression gene and plays a crucial role in the maintenance of the nontumorigenic phenotype of cells. Mutation of the p53 gene confers the greatest known predisposition to cancer formation.

The p53 mutation is present in a wide range of cancers $(148,149,156)$, and typically constitutes one mutation in a cascade of sequential mutations in a number of genes (148). Approximately $50 \%$ to $60 \%$ of human cancers are associated with a mutated p53 gene or lack of p53 expression $(149,157,158)$. p53-deficient cancers are often unstable, aggressive, and resistant to therapy (157). In vitro studies involving restoration of wild-type p53 expression in cultured tumor cells have demonstrated impressive inhibition of cell growth (149,158-161), return to anchorage-dependent growth (161), morphologic change (161), decreased colony formation $(149-152,159,162)$, selectively induced apoptosis of cancer cells $(163,164)$, and sensitization of tumor cells to chemotherapy and radiation therapy $(165,166)$ in a number of tumor systems. A variety of animal models have revealed that wild-type p53 transfection leads to suppression of tumorigenicity $(148,167)$, prevention of tumor formation $(87,168)$, decreased tumor growth $(87,148,149,151-153,160)$, induction of apoptosis $(160)$, tumor regression $(87,169)$, decreased metastasis $(148,149,151-153,169)$, and even long-term survival $(148,149,151-153,158,168)$. This evidence suggests that p53, is an excellent target 
candidate for cancer gene therapy.

However, the conformation-dependent nature of p53 function renders the genetic aberration more complex than a simple loss of function. In the "wild-type" conformation, p53 is most often (but not always) a repressor of cell growth (38), whereas p53 in the "mutant" conformation may not be equivalent to loss of p53 function alone. Some of the mutated p53 gene products may act as promoters of cell growth (149) and may manifest as dominant-negative mutants. Still other p53 mutants may act through gain-of-function to enhance the tumorigenic phenotype, in essence serving as oncogenes.

Based on a knowledge of the complexity of p53, several clinical trials targeting this gene have been initiated. These protocols range from introducing wild-type p53 into tumor cells to using antisense p53 to eliminate mutated p53 (38,87-89). Both animal experiments (170) and clinical studies (87) suggest that these approaches have limited toxicity, although efficacy has yet to be evaluated.

\section{Additional Considerations}

Theoretically, genetic suppression of the tumor phenotype may provide a more physiological approach to cancer treatment. Animal and human studies with antisense oligonucleotides (86), antisense c-fos vector (154), and recombinant wild-type p53 adenovirus have shown no evidence of toxicity. However, cancer is a disease with complex genetic changes. Between the two extremes--oncogenes and tumor-suppressor genes-lie a number of additional mechanisms apparently involved in the development of neoplasms. Most human cancers are likely to result from multiple interacting genetic defects, none of which alone is sufficient but all of which are required for tumor development to occur. The phenomenon of suppression of tumorigenicity with a foreign gene depends on the function encoded by the gene and the role that the gene plays in determining replication and differentiation processes in the cell. In some cancer cells, suppressor functions may be less important than other functions in determining the aberrant phenotype. Therefore, genetic transfer of an individual suppressor gene might, in itself, be ineffective in altering the aberrant properties. The complexity of the p53 gene and the failure of the Rb gene to revert prostate cancer cell growth and morphologic change to normal (148) are both prime examples. Furthermore, there is no assurance that the same techniques will be feasible for all oncogenes, all tumor-suppressor genes, or all types of cancer. Choice of correction genes must be guided by detailed characterization of each genetic defect in an individual tumor. However, for selected models (38), most notably Rb and p53 genetic transfer does seem to produce a reversion of features of the cancer phenotype to normal.

\section{FUTURE DIRECTIONS}

Loss of growth control and metastasis are the two major features of malignant tumors. Whereas primary tumors can be easily removed by surgery, metastatic tumors remain difficult to treat and are a major cause of death. Theoretically, only a single cancer cell is necessary to generate a tumor. Therefore, the ability of a therapeutic strategy to target metastatic tumor and to eliminate $100 \%$ of cancer cells is essential for eradication of cancer and should be the goal of cancer therapeutic strategies.

Proper delivery of a therapeutic gene into cells is the first critical step for successful gene therapy. High transfection efficiency as well as selective and specific cancer targeting in vivo are the two most important technical tasks and remain under extensive research. The current technology does not yet permit $100 \%$ transfection efficiency of cancer cells in vivo. However, the immunomodulatory and suicide strategies may bypass this technical obstacle, as they are designed to be fully effective with only partial transfection of the cancer cell. Furthermore, the strategies directed toward suppression of tumor phenotype may be used to reduce tumor burden, even without $100 \%$ transfection efficiency.

Ex vivo gene transfer and local intra-tumor injection can effectively transfer the gene into a specific cell 
group. However, systemic tumor-specific targeting, upon which metastatic tumor targeting may depend, is likely to require different approaches. Researchers are currently attempting to accomplish this technical task by targeting tumor cells through tumor-specific

ligand-cell-surface-receptor interactions and through control of transgene expression in tumor tissue by tumor-specific promoters $(118,171-176)$. Compared to other strategies, the immunomodulatory modalities, designed to elicit systemic anti-tumor effects, have the advantage of targeting metastatic tumor.

\section{CONCLUSION}

Cancer gene therapy may provide a novel tool with considerable advantages over conventional cancer therapy, particularly in the areas of efficacy and toxicity. Nevertheless, numerous limitations remain for gene therapy, as for most cancer therapies. Cancer treatment is complicated by the fact that malignancy represents a highly complex form of disease, especially in the case of the most advanced tumors, and it is becoming increasingly clear that many cancers may not be curable by single-modality therapy. Carefully selected combinations of strategies may prove more efficient, especially where synergism may be evident. For example, transfer of wild-type p53 appears to sensitize tumor cells to chemotherapy or radiation therapy and induce apoptosis of these cells (165). Furthermore, more detailed classification and diagnosis at the molecular level are required to enable clinicians to make more informed choices regarding appropriate individualized therapeutic strategies.

It is remarkable to note the strides made in the area of gene therapy in less than a decade. Cancer gene therapy is truly a field born of the direct translation of basic research into clinical application. Although a great deal of research is yet to be done and many technical problems to be solved, the intense interest and vast number of ongoing studies in this area will soon provide the clinical data necessary for critical evaluation of, and future advances in, cancer gene therapy.

\section{ACKNOWLEDGMENTS}

The author wishes to thank Dr. James A. Zwiebel for his guidance in planning the scope of this review, and to Dr. Zwiebel, Dr. Erik W. Thompson and Douglass A. Cattel for helpful critique of the manuscript.

\section{REFERENCES}

1. Blaese RM, Anderson WF, Culver K. The ADA human gene therapy clinical protocol. Human Gene Therapy 1: 327-62; 1990.

2. Bordignon C, Notarangelo LD, Nobili N, et al. Gene therapy in peripheral blood lymphocytes and bone marrow for ADA- immunodeficient patients. Science 270: 470-5; 1995.

3. Blaese RM, Culver KW, Miller AD, et al. T lymphocyte-directed gene therapy for ADA- SCID: Initial trial results after 4 years. Science 270: 475-80; 1995.

4. James ND, Sikora K. Tumor-associated antigens. In: Lachmann PJ, Peters SK, Rosen FS, and Walport MJ, editors. Clinical Aspects of Immunology. Oxford: Blackwell Scientific Publications, 1993.

5. Lurquin C, Van Pel A, Mariame B. Structure for the gene coding for tumor antigen P91A: a peptide encoded by the mutated exon is recognized with Ld by cytolytic T cells. Cell 58:293-303; 1989.

6. Van Der BP., Traversari C, Chomez P, et al. A gene encoding an antigen recognized by cytotoxic $\mathrm{T}$ lymphocytes on a human melanoma. Science 254: 1643-8; 1991.

7. Forni G, Varesio L, Giovarelli M, et al. Dynamic state of spontaneous immune reactivity towards a 
mammary adenocarcinoma. In: Spreafico F, Arnon R, editors. Tumor-Associated Antigens and Their Specific Immune Response.London: Academic Press, 1979.

8. Pierro FD, Cavallo F, Pericle F, et al. Strategies for cytokine utilization in tumor therapy. Medical Oncology and Tumor Pharmacotherapy 10: 53-9; 1993.

9. Zatloukal K, Schmidt W, Cotten M, et al. Somatic gene therapy for cancer: the utility of transfer infection in generating 'tumor vaccines'. Gene 135: 199-207; 1993.

10. Zwiebel JA, Su N, MacPherson A, et al. The gene therapy of cancer: transgenic immunotherapy. Seminars in Hematology 30: 119-29; 1993.

11. Rosenberg SA. The immunotherapy of solid cancers based on cloning the genes encoding tumor-rejection antigens. Annual Review of Medicine 47: 481-91; 1996.

12. Graham RA, Burchell JM, Taylor-Papadimitriou J. The polymorphic epithelial mucin: Potential as an immunogen for a cancer vaccine. Cancer Immunology, Immunotherapy 42: 71-80; 1996.

13. Culver KW. Clinical applications of gene therapy for cancer. Clinical Chemistry 40: 510-2.; 1994

14. Pardoll D. Immunotherapy with cytokine gene-transduced tumor cells: the next wave in gene therapy for cancer. Current Opinion in Oncology 4: 1124-9; 1992.

15. Borysiewicz LK, Fiander A, Nimako M, et al. A recombinant vaccinia virus encoding human papillomavirus types 16 and 18, E6 and E7 proteins as immunotherapy for cervical cancer. Lancet 347: 15237; 1996.

16. Schlom J, Kantor J, Abrams S, et al. Strategies for the development of recombinant vaccines for the immunotherapy of breast cancer. Breast Cancer Research and Treatment 38: 27-39; 1996.

17. Rosenberg SA, White DE. Vitiligo in patients with melanoma: Normal tissue antigens can be targets for cancer immunotherapy. Journal of Immunotherapy 19: 81-4; 1996.

18. Roth J, Dittmer D, Rea D, et al. p53 as a target for cancer vaccines: Recombinant canarypox virus vectors expressing p53 protect mice against lethal tumor cell challenge. Proceedings of the National Academy of Sciences of the United Steates of America 93: 4781-6; 1996.

19. Reiser H, Schneeberger EE. Expression and function of B7-1 and B7-2 in hapten-induced contact sensitivity. European Journal of Immunology 26: 880-5; 1996.

20. Gause WC, Urban JF, Linsley P, et al. Role of B7 signaling in the differentiation of naive CD4+ T cells to effector interleukin-4-producing T helper cells. Immunologic Research 14: 176-88; 1995.

21. Ghiotto-Ragueneau M, Battifora M, Truneh A, et al. Comparison of CD28-B7.1 and B7.2 functional interaction in resting human T cells: Phosphatidylinositol 3-kinase association to CD28 and cytokine production. European Journal of Immunology 26: 34-41; 1996.

22. Natesan M, Razi-Wolf Z, Reiser H. Costimulation of IL-4 production by murine B7-1 and B7-2 molecules. Journal of Immunology 156: 2783-91; 1996.

23. Zhang YQ, Van Neerven RJJ, Kasran A, et al. Differential requirements for co-stimulatory signals from B7 family members by resting versus recently activated memory T cells towards soluble recall antigens. 
International Immunology 8: 37-44; 1996.

24. Baskar S, Clements VK, Glimcher LH, et al. Rejection of MHC class II-transfected tumor cells requires induction of tumor-encoded B7-1 and/or B7-2 costimulatory molecules. Journal of Immunology 156:3821-7; 1996.

25. Chen L, Ashe S, Brady WA. Costimulation of antitumor immunity by the B7 counter receptor for the T lymphocyte molecules CD28 and CTLA-4. Cell 71: 1093-102; 1992.

26. Honma S, Tsukada S, Honda S. Biological-clinical significance of selective loss of HLA-class-I allelic product expression in squamous-cell carcinoma of the uterine cervix. International Journal of Cancer (United States) 57: 650-5; 1994.

27. Haddada H, Ragot T, Cordier L, et al. Adenoviral interleukin-2 gene transfer into P815 tumor cells abrogates tumorigenicity and induces antitumoral immunity in mice. Human Gene Therapy 4: 703-11; 1993.

28. Rosenberg SA, Anderson WF, Blaese MR, et al. Immunization of cancer patients using autologous cancer cells modified by insertion of the gene for interleukin-2. Human Gene Therapy 3: 75-90; 1992.

29. Chaux P, Moutet M, Faivre J, et al. Inflammatory cells infiltrating human colorectal carcinomas express HLA classII but not B7-1 and B7-2 costimulatory molecules of the T-cell activation. Laboratory Investigation 74: $975-83 ; 1996$.

30. Ellis JR, Keating PJ, Baird J, et al. The association of an hpv16 oncogene variant with HLA-B7 has implications for vaccine design in cervical cancer. Nature Medicine 1: 464-70; 1995.

31. La Motte RN, Rubin MA, Barr E, et al. Therapeutic effectiveness of the immunity elicited by P815 tumor cells engineered to express the B7-2 costimulatory molecule. Cancer Immunology, Immunotherapy 42: 161$9 ; 1996$.

32. Dunussi-Joannopoulos K, Weinstein HJ, Nickerson PW, et al. Irradiated B7-1 transduced primary acute myelogenous leukemia (AML) cells can be used as therapeutic vaccines in murine AML. Blood 87: 2938-46; 1996.

33. Fujii H, Inobe M, Kimura F, et al. Vaccination of tumor cells transfected with the B7-1 (CD80) gene induces the anti-metastatic effect and tumor immunity in mice. International Journal of Cancer 66: 219-24; 1996.

34. Wang YC, Zhu LH, McHugh R, et al. Induction of autologous tumor-specific cytotoxic T-lymphocyte activity against a human renal carcinoma cell line by B7-1 (CD80) costimulation. Journal of Immunotherapy 19: 1-8; 1996.

35. MinasiaN LM, Gansbacher B. Second International Conference on Gene Therapy of Cancer. Annual of Oncology 5: 313-6; 1994.

36. Townsend SE, Allison JP. Tumor rejection after direct costimulation of CD8+ T cell by B7-transfected melanoma cells. Science 259: 369-71; 1993.

37. Conry RM, LoBuglio AF, Curiel DT. Phase Ia trial of a polynucleotide anti-tumor immunization to human carcinoembryonic antigen in patients with metastatic colorectal cancer. Human Gene Therapy 7: 755$72 ; 1996$. 
38. Clinical Protocols. Cancer Gene Therapy 3: 265-78; 1996.

39. Nabel GJ, Nabel EG, Yang Z, et al. Molecular genetic interventions for cancer. Cold Spring Harbor Symposia on Quantitative Biology 59: 699-707; 1994.

40. Hersh EM, Akporiaye E, Harris D, et al. Phase I study of immunotherapy of malignant melanoma by direct gene transfer. Human Gene Therapy 5: 1371-84; 1994.

41. Nabel GJ, Yang ZY, Nabel EG, et al. Direct gene transfer for treatment of human cancer. Ann N Y Acad Sci 772: 227-31; 1995.

42. Nabel GJ, Nabel EG, Yang ZY, et al. Direct gene transfer with DNA-liposome complexes in melanoma: expression, biologic activity, and lack of toxicity in humans. Proceedings of the National Academy of Science of the USA 90: 11307-11; 1993.

43. Immunotherapy of malignancy by in vivo gene transfer into tumors. Human Gene Therapy 3: 399-410; 1992.

44. Nabel EG, Yang Z, Muller D, et al. Safety and toxicity of catheter gene delivery to the pulmonary vasculature in a patient with metastatic melanoma. Human Gene Therapy 1994;5:1089-94.

45. Response to the points to consider for immunotherapy of malignancy by in vivo gene transfer into tumors. Human Gene Therapy 3: 705-11; 1992.

46. Parmiani G, Colombo MP. Somatic gene therapy of human melanoma: preclinical studies and early clinical trials Somatic gene therapy of human melanoma: preclinical studies and early clinical trials. Melanoma Research 5: 295-301; 1995.

47. Nabel GJ, Chang AE, Nabel EG, et al. Immunotherapy for cancer by direct gene transfer into tumors. Human Gene Therapy 5: 57-77; 1994.

48. Berns AJ, Clift S, Cohen LK, et al. Phase I study of non-replicating autologous tumor cell injections using cells prepared with or without GM-CSF gene transduction in patients with metastatic renal cell carcinoma. Human Gene Therapy 6: 347-68; 1995.

49. Poplin EA, Alberts DS, Rinehart JJ, et al. GM-CSF, carboplatin, doxorubicin: a phase I study. Cancer Chemother Pharmacol 33: 340-6; 1994.

50. Chang AE, Sondak VK, Bishop DK, et al. Adoptive immunotherapy of cancer with activated lymph node cells primed in vivo with autologous tumor cells transduced with the GM-CSF gene. Human Gene Therapy 7: 773-92; 1996.

51. Wong L, Taylor CW, Radwanski E, et al. Comparison of 4- and 24-hour intravenous infusion schedules for granulocyte-macrophage colony-stimulating factor. Journal of Immunotherapy with Emphasis on Tumor Immunology 18: 57-65; 1995.

52. Gansbacher B, Houghton A, Livingston P, et al. A pilot study of immunization with HLA-A2 matched allogenic melanoma cells that secrete interleukin-2 in patients with metastatic melanoma. Human Gene Therapy 3: 677-90; 1992.

53. Gansbacher B, Motzer R, Houghton A, et al. A pilot study of immunization with interleukin-2 secreting allogenic HIA-A2 matched renal cell carcinoma cells in patients with advanced renal cell carcinoma. Human 
Gene Therapy 3: 691-703; 1992.

54. Economou JS, Figlin RA, Jacobs E, et al. The treatment of patients with metastatic melanoma and renal cell cancer using in vitro expanded and genetically-engineered (neomycin phosphotransferase) bulk, CD8(+) and /or CD4(+) tumor infiltrating lymphocytes and bulk, CD8(+) and /or CD4(+) peripheral blood leukocytes in combination with recombinant interleukin-2 alone or with recombinant interleukin-2 and recombinant alpha interferon. Human Gene Therapy 3: 411-30; 1992.

55. Osanto S, Brouwenstyn N, Vaessen N, et al. Immunization with interleukin-2 transfected melanoma cells. a phase I-II study in patients with metastatic melanoma. Human Gene Therapy 4: 323-30; 1993.

56. Stingl G, Brocker EB, Mertelsmann R, et al. Phase I study to the immunotherapy of metastatic malignant melanoma by a cancer vaccine consisting of autologous cancer cells transfected with the human IL-2 gene. Human Gene Therapy 7: 551-63; 1996.

57. Sobol RE, Royston I, Fakhrai H, et al. Injection of colon carcinoma patients with autologous irradiated tumor cells and fibroblasts genetically modified to secrete interleukin-2 (IL-2): a phase I study. Human Gene Therapy 6: 195-204; 1995.

58. Human gene therapy clinical trials in Europe. Human Gene Therapy 7: 1258-9; 1996.

59. Suminami Y, Elder EM, Lotze MT, et al. In situ interleukin-4 gene expression in cancer patients treated with genetically modified tumor vaccine. Journal of Immunotherapy with Emphasis on Tumor Immunology 17: 238-48; 1995.

60. Lotze MT, Rubin JT, Carty S, et al. Gene therapy of cancer: a pilot study of IL-4-gene-modified fibroblasts admixed with autologous tumor to elicit an immune response. Human Gene Therapy 5: 41-55; 1994.

61. Cascinelli N, Foa R, Parmiani G, et al. Active immunization of metastatic melanoma patients with interleukin-4 transduced, allogenic melanoma cells. a phase I-II study. Human Gene Therapy 5: 1059-64; 1994.

62. Mackiewicz A, Gorny A, Laciak M, et al. Gene therapy of human melanoma. immunization of patients with autologous tumor cells admixed with allogenic melanoma cells secreting interleukin 6 and soluble interleukin 6 receptor. Human Gene Therapy 6: 805-11; 1995.

63. Schmidt-Wolf IG, Huhn D, Neubauer A, et al. Interleukin-7 gene transfer in patients with metastatic colon carcinoma, renal cell carcinoma, melanoma, or with lymphoma. Human Gene Therapy 5: 1161-8; 1994.

64. Tahara H, Lotze MT. Antitumor effects of interleukin-12 (IL-12): applications for the immunotherapy and gene therapy of cancer. Gene Therapy 2: 96-106; 1995.

65. Tahara H, Lotze MT, Robbins PD, et al. IL-12 gene therapy using direct injection of tumors with genetically engineered autologous fibroblasts. Human Gene Therapy 6: 1607-24; 1995.

66. Meyskens FL, Jr., Kopecky KJ, Taylor CW, et al. Randomized trial of adjuvant human interferon gamma versus observation in high-risk cutaneous melanoma: a southwest oncology group study. Journal of the National Cancer Institute 87: 1710-3; 1995.

67. Seigler HF, Darrow TL, Abdel-Wahab Z, et al. A phase I trial of human gamma interferon transduced 
autologous tumor cells in patients with disseminated malignant melanoma. Human Gene Therapy 5: 761-77; 1994.

68. Immunization of cancer patients using autologous cancer cells modified by insertion of the gene for tumor necrosis factor. Human Gene Therapy 3: 57-73; 1992.

69. Rosenberg SA, Anderson WF, Blaese M, et al. The development of gene therapy for the treatment of cancer. Annals of Surgery 218: 455-63; 1993.

70. Bordignon C, Bonini C, Verzeletti S, et al. Transfer of the HSV-tk gene into donor peripheral blood lymphocytes for in vivo modulation of donor anti-tumor immunity after allogenic bone marrow transplantation. Human Gene Therapy 6: 813-9; 1995.

71. Oldfield EH, Ram Z, Chiang Y, et al. Intrathecal gene therapy for the treatment of leptomeningeal carcinomatosis. gti 0108. a phase I/II study. Human Gene Therapy 6: 55-85; 1995.

72. Kun LE, Gajjar A, Muhlbauer M, et al. Stereotactic injection of herpes simplex thymidine kinase vector producer cells (pa317-g1tk1svna.7) and intravenous ganciclovir for the treatment of progressive or recurrent primary supratentorial pediatric malignant brain tumors. Human Gene Therapy 6: 1231-55; 1995.

73. Klatzmann D, Philippon J, Valery CA, et al. Gene therapy for glioblastoma in adult patients: Safety and efficacy evaluation of an in situ injection of recombinant retroviruses producing cells carrying the thymidine kinase gene of the herpes simplex type 1 virus, to be followed with the administration of ganciclovir. Human Gene Therapy 7: 109-26; 1996.

74. Klatzmann D, Herson S, Cherin P, et al. Gene therapy for metastatic malignant melanoma: Evaluation of tolerance to intratumoral injection of cells producing recombinant retroviruses carrying the herpes simplex virus type 1 thymidine kinase gene, to be followed by ganciclovir administration. Human Gene Therapy 7: 255-67; 1996.

75. Raffel C, Culver K, Kohn D, et al. Gene therapy for the treatment of recurrent pediatric malignant astrocytomas with in vivo tumor transduction with the herpes simplex thymidine kinase gene/ganciclovir system. Human Gene Therapy 5: 863-90; 1994.

76. Culver KW, Van Gilder J, Link CJ, et al. Gene therapy for the treatment of malignant brain tumors with in vivo tumor transduction with the herpes simplex thymidine kinase gene/ganciclovir system. Human Gene Therapy 5: 343-79; 1994.

77. Oldfield EH, Ram Z, Culver KW, et al. Gene therapy for the treatment of brain tumors using intra-tumoral transduction with the thymidine kinase gene and intravenous ganciclovir. Human Gene Therapy 4: 39-69; 1993.

78. Whartenby KA, Abraham GN, Calabresi PA, et al. Gene-modified cells for the treatment of cancer. Pharmacology and Therapeutics 66: 175-90; 1995.

79. Link CJ, Jr., Moorman D, Seregina T, et al. A phase I trial of in vivo gene therapy with the herpes simplex thymidine kinase/ganciclovir system for the treatment of refractory or recurrent ovarian cancer. Human Gene Therapy 7: 1161-79; 1996.

80. Eck SL, Alavi JB, Alavi A, et al. Treatment of advanced CNS malignancies with the recombinant adenovirus H5.010RSVTK: A Phase I trial. Human Gene Therapy 7: 1465-82; 1996. 
81. Hesdorffer C, Antman K, Bank A, et al. Human mdr gene transfer in patients with advanced cancer. Human Gene Therapy 5: 1151-60; 1994.

82. Deisseroth AB, Kavanagh J, Champlin R. Use of safety-modified retroviruses to introduce chemotherapy resistance sequences into normal hematopoietic cells for chemoprotection during the therapy of ovarian cancer: a pilot trial. Human Gene Therapy 5: 1507-22; 1994.

83. Deisseroth AB, Holmes F, Hortobagyi G, et al. Use of safety-modified retroviruses to introduce chemotherapy resistance sequences into normal hematopoietic cells for chemoprotection during the therapy of breast cancer: A pilot trial. Human Gene Therapy 7: 401-16; 1996.

84. Holt JT, Arteaga CB, Robertson D, et al. Gene therapy for the treatment of metastatic breast cancer by in vivo transduction with breast-targeted retroviral vector expressing antisense c-fos RNA. Human Gene Therapy 7: 1367-80; 1996.

85. Johnson TR, Trojan J, Anthony DD, et al. Gene therapy of rat brain glioblastoma by an episome-based transcriptional cassette expressing antisense igf-i cDNA. Indian Journal of Biochemistry and Biophysics 31: $1-13 ; 1994$.

86. Bishop MR, Iversen PL, Bayever E, et al. Phase I trial of an antisense oligonucleotide ol(1)p53 in hematologic malignancies. J Clinical Oncology 14: 1320-6; 1996.

87. Roth JA. Gene replacement strategies for cancer. Israel Journal of Medical Sciences 32: 89-94; 1996.

88. Roth JA. Modification of tumor suppressor gene expression and induction of apoptosis in non-small cell cancer (NSCLC) with an adenovirus vector expressing wildtype p53 and Cisplatin. Human Gene Therapy 7: 1013-30; 1996.

89. Roth JA. Modification of tumor suppressor gene expression in non-small cell lung cancer (NSCLC) with a retroviral vector expressing wildtype (normal) p53. Human Gene Therapy 7: 861-74; 1996.

90. Sobol RE, Scanlon KJ. Cancer Gene Therapy-Clinical Perspective 1995. Cancer Gene Therapy 3: 3; 1996.

91. Williams IR, Ort RJ, Daley D, et al. Constitutive expression of B7-1 (CD80) on mouse keratinocytes does not prevent development of chemically induced skin papillomas and carcinomas. Journal of Immunology 156: 3382-8; 1996.

92. Li YW, Hellström KE, Newby SA, et al. Costimulation by CD48 and B7-1 induces immunity against poorly immunogenic tumors. Journal of Experimental Medicine 183: 639-44; 1996.

93. Creery WD, Diaz-Mitoma F, Filion L, et al. Differential modulation of B7-1 and B7-2 isoform expression on human monocytes by cytokines which influence the development of T helper cell phenotype. European Journal of Immunology 26: 1273-7; 1996.

94. Ozawa H, Aiba S, Nakagawa S, et al. Interferon-gamma and interleukin-10 inhibit antigen presentation by Langerhans cells for T helper type 1 cells by suppressing their CD80 (B7-1) expression. European Journal of Immunology 26: 648-52; 1996.

95. Ozawa $\mathrm{H}$, Nakagawa $\mathrm{S}$, Tagami $\mathrm{H}$, et al. Interleukin- $1 \mathrm{~b}$ and granulocyte macrophage colony-stimulating factor mediate langerhans cell maturation differently. Journal of Investigative Dermatology 106: 441-5; 1996. 
96. Rao JB, Chamberlain RS, Bronte V, et al. IL-12 is an effective adjuvant to recombinant vaccinia virusbased tumor vaccines - Enhancement by simultaneous B7-1 expression. Journal of Immunology 156: 3357$65 ; 1996$.

97. Foa R, Cignetti A, Riera L, et al. Cytokine gene therapy in oncology. Folia Biologiea 40: 37-48; 1994.

98. Hodge JW, Abrams S, Schlom J, et al. Induction of antitumor immunity by recombinant vaccinia viruses expressing B7-1 or B7-2 costimulatory molecules. Cancer Research 54: 5552-5; 1994.

99. Arient F, Sule-Suso J, Melani C, et al. Interleukin-2 gene-transduced human melanoma cells efficiently stimulate MHC-Unrestricted and MHC-Restricted autologous lymphocytes. Human Gene Therapy 5: 1139$50 ; 1994$.

100. Dranoff G, Jaffee E, Lazenby A, et al. Vaccination with irradiated tumor cells engineered to secrete murine granulocyte-macrophage colony- stimulating factor stimulates potent, specific, and long- lasting antitumor immunity. Proceedings of the Nattional Academy of Sciences of the USA 90: 3539-43; 1993.

101. McGary CT and Welch DR. Highly metastatic $13762 \mathrm{NF}$ rat mammary adenocarcinoma clones secrete IL-3 or GM-CSF like activity. Proceedings for 86th American Association for Cancer Research 36: 76Abs456; 1995.

102. Roncaroli F and Cavalieri M. Receptor for GM-CSF in axillary lymph-nodal metastasis of human breast carcinomas. Proceedings for 86th American Association for Cancer Research 36: 80Abs478; 1995.

103. Ruco L. Tumor-infiltrating leukocytes: Histology, immunohistochemistry and in situ hybridization. In: Mantovani A, R.G.T2 - Tumor- Associated Leukocytes: Pathophysiology and Therapeutic Applications, editor. Austin: Landes Company, 1996.

104. Hwu P, Rosenberg SA. The use of gene-modified tumor- infiltrating lymphocytes for cancer therapy. Annals of the New York Academy of Sciences 716: 188-99; 1994.

105. Rodenberg SA, Yannelli JR, Yang JC, et al. Treatment of patient with metastatic melanoma with autologous tumor- infiltrating lymphocytes and interleukin 2. Journal of the National Cancer Institute 86: 1159-66; 1994.

106. Nakamura Y, Wakimoto H, Abe J, et al. Adoptive immunotherapy with murine tumor-specific T lymphocytes engineered to secrete interleukin 2. Cancer Research 54: 5757-60; 1994.

107. Rodenberg A, Anderson WF, Blaese M, et al. The development of gene therapy for the treatment of cancer. Annals of Surgery 218: 455-64; 1993.

108. Primus FJ, Finch MD, Wetzel SA, et al. Monoclonal antibody gene transfer, implications for tumorspecific cell-mediated cytotoxicity. Ann N Y Acad Sci 716: 154-66; 1994.

109. Moolten FL. An Alternative to the magic bullet paradigm for specific cancer therapy. Medical Hypotheses 24: 43-51; 1987.

110. Moolten FL, Wells JM, Heyman RA, et al. Lymphoma regression induced by ganciclovir in mice bearing a herpes thymidine kinase transgene. Human Gene Therapy 1: 125-34; 1990.

111. Huber BE, Richards CA, Krenitsky TA. Retroviral-mediated gene therapy for the treatment of hepatocellular carcinoma: an innovative approach for cancer therapy. Proceedings of the National Academy 
of Sciences in the United States of America. 88: 8039-43; 1991.

112. Huber BE, Richards CA, Austin EA. Virus-directed enzyme/prodrug therapy (VDEPT). Annals of the New York Academy of Sciences 716: 104-14; 1994.

113. Austin E, Huber B. A first step in the development of gene therapy for colorectal carcinoma: cloning, sequencing, and expression of escherichia coli cytosine deaminase. Molecular Pharmacology 43: 380-7; 1993.

114. Culver KW, Ram Z, Wallbridge S, et al. In vivo gene transfer with retroviral vector-producer cells for treatment of experimental brain tumor. Science 256: 1550-2; 1992.

115. Smith MJ, Rousculp MD, Goldsmith KT, et al. Surfactant protein a-directed toxin gene kills lung cancer cells in vitro. Human Gene Therapy 5: 29-35; 1994.

116. Sikora K, Harris J, Hurst H, et al. Therapeutic strategies using c-erbb-2 promoter-controlled drug activation. Annals of the New York Academy of Sciences 716: 115-24; 1994.

117. Chen S, Shine HD, Goodman JC, et al. Gene therapy for brain tumors: regression of experimental gliomas by adenovirus-mediated gene transfer in vivo. Proceedings of the National Academy of Science of the USA 91: 3054-7; 1994.

118. Kumagai T, Tanio Y, Osaki T, et al. Eradication of myc-overexpressing small cell lung cancer cells transfected with herpes simplex virus thymidine kinase gene containing myc-max response elements. Cancer Research 56: 354-8; 1996.

119. Bonnekoh B, Greenhalgh DA, Bundman DS, et al. Inhibition of melanoma growth by adenoviralmediated hsv thymidine kinase gene transfer in vivo. Journal of Investigative Dermatology 104: 313-7; 1995

120. Sacco MG, Mangiarini L, Villa A, et al. Local regression of breast tumors following intramammary ganciclovir administration in double transgenic mice expressing neu oncogene and herpes simplex virus thymidine kinase. Gene Therapy 2: 493-7; 1995.

121. Hwang HC, Smythe WR, Elshami AA, et al. Gene therapy using adenovirus carrying the herpes simplex-thymidine kinase gene to treat in vivo models of human malignant mesothelioma and lung cancer. American Journal of Respiratory Cell and Molecular Biology 13: 7-16; 1995.

122. Yoshida K, Kawami H, Yamaguchi Y, et al. Retrovirally transmitted gene therapy for gastric carcinoma using herpes simplex virus thymidine kinase gene. Cancer 75: 1467-71; 1995.

123. O'Malley BW, Jr., Chen SH, Schwartz MR, et al. Adenovirus-mediated gene therapy for human head and neck squamous cell cancer in a nude mouse model. Cancer Research 55: 1080-5; 1995.

124. Smythe WR, Hwang HC, Elshami AA, et al. Treatment of experimental human mesothelioma using adenovirus transfer of the herpes simplex thymidine kinase gene. Annals of Surgery 222: 78-86; 1995.

125. Vrionis FD, Wu JK, Qi PM, et al. Tumor cells expressing the herpes simplex virus thymidine kinase gene in the treatment of Walker 256 meningeal neoplasia in rats. Journal of Neurosurgery 84: 250-7; 1996.

126. Tong XW, Block A, Chen SH, et al. In vivo gene therapy of ovarian cancer by adenovirus-mediated thymidine kinase gene transduction and ganciclovir administration. Gynecologic Oncology 61: 175-9; 1996. 
127. Colak A, Goodman JC, Chen SH, et al. Adenovirus-mediated gene therapy in an experimental model of breast cancer metastatic to the brain. Human Gene Therapy 6: 1317-22; 1995.

128. Colak A, Goodman JC, Chen SH, et al. Adenovirus-mediated gene therapy for experimental spinal cord tumors: tumoricidal efficacy and functional outcome. Brain Research 691: 76-82; 1995.

129. Freeman SM, Abboud CN, Whartenby KA, et al. The "bystander effect": tumor regression when a fraction of the tumor mass is genetically modified. Cancer Research 53: 5274-83; 1993.

130. Chen CY, Chang YN, Ryan P, et al. Effect of herpes simplex virus thymidine kinase expression levels on ganciclovir-mediated cytotoxicity and the "bystander effect". Human Gene Therapy 6: 1467-76; 1995.

131. Kaneko Y, Tsukamoto A. Gene therapy of hepatoma: bystander effects and non-apoptotic cell death induced by thymidine kinase and ganciclovir. Cancer Letters 96: 105-10; 1995.

132. Marini FC, 3rd, Nelson JA, Lapeyre JN. Assessment of bystander effect potency produced by intratumoral implantation of hsvtk-expressing cells using surrogate marker secretion to monitor tumor growth kinetics. Gene Therapy 2: 655-9; 1995.

133. Fick J, Barker FG, 2nd, Dazin P, et al. The extent of heterocellular communication mediated by gap junctions is predictive of bystander tumor cytotoxicity in vitro. Proceedings of the National Academy of Science of the USA 92: 11071-5; 1995.

134. Kuriyama S, Nakatani T, Masui K, et al. Bystander effect caused by suicide gene expression indicates the feasibility of gene therapy for hepatocellular carcinoma Bystander effect caused by suicide gene expression indicates the feasibility of gene therapy for hepatocellular carcinoma. Hepatology 22: 1838-46; 1995.

135. Elshami AA, Kucharczuk JC, Sterman DH, et al. The role of immunosuppression in the efficacy of cancer gene therapy using adenovirus transfer of the herpes simplex thymidine kinase gene. Annals of Surgery 222: 298-10; 1995.

136. Culver KW, Moorman DW, Muldoon RR, et al. Toxicity and immunologic effects of in vivo retrovirusmediated gene transfer of the herpes simplex-thymidine kinase gene into solid tumors. Cold Spring Harbor Symposium on Quantitative Biology 59: 685-90; 1994.

137. Trinh QT, Austin EA, Murray DM, et al. Enzyme/prodrug gene therapy: comparison of cytosine deaminase/5-fluorocytosine versus thymidine kinase/ganciclovir enzyme/prodrug systems in a human colorectal carcinoma cell line. Cancer Research 55: 4808-12; 1995.

138. Bi WL, Parysek LM, Warnick R, et al. In vitro evidence that metabolic cooperation is responsible for the bystander effect observed with HSV tk retroviral gene therapy. Human Gene Therapy 4: 725-31; 1993.

139. Barba D, Hardin J, Sadelain M, et al. Development of anti-tumor immunity following thymidine kinasemediated killing of experimental brain tumors. Proceedings of the National Academy of Sciences of the USA 91:4348-52; 1994.

140. Eastham JA, Hall SJ, Sehgal I, et al. In vivo gene therapy with p53 or p21 adenovirus for prostate cancer. Cancer Research 55: 5151-5; 1995.

141. Cai DW, Mukhopadhyay T, Roth JA. Suppression of lung cancer cell growth by ribozyme-mediated modification of p53 pre-mRNA. Cancer Gene Therapy 2: 199-205; 1995. 
142. Milligan JF, Jomes RJ, Froehler BC, et al. Development of antisense therapeutics. Annals of the New York Academy of Sciences 716: 228-41; 1994.

143. Scanlon KJ. Therapeutic application of anti-oncogene ribozymes in cancer. Proceedings for 86th American Association for Cancer Research 36: 653; 1995.

144. Normanno N, Bianco C, Damiano V, et al. Growth inhibition of human colon carcinoma cells by antiEGF-related growth factors antisense oligonucliotides. Proceedings for 86th American Association for Cancer Research 36: 431 Abs2571; 1995.

145. Gewirtz AM. Oligodeoxynucleotides as therapeutic agents for human leukemia. Proceedings for 86th American Association for Cancer Research 36: 654; 1995.

146. Ohta Y, Tone T, Shitara T, et al. H-ras ribozyme-mediated alteration of the human melanoma phenotype. Annals of the New York Academy of Sciences 716: 242-56; 1994.

147. Hynes NE, Beerli RR, Graus-Porta D. Single-chain antibody-mediated intracellular retention of ErbB-2 reverts transformation and impairs NDF and EGF signaling. Proceedings for 86th American Association for Cancer Research 36: 424Abs 2529; 1995.

148. Friedman T. Gene therapy of cancer through restoration of tumor-suppressor function? Cancer 70 (6 suppl):1810-7; 1990.

149. Roemer K, Friedmann T. Mechanisms of action of the p53 tumor suppressor and prospects for cancer gene therapy by reconstitution of p53 function. Annals of the New York Academy of Sciences 716: 265-82; 1994.

150. Hamada K, Zhang W, Alemany R, et al. Growth inhibition of human cervical cancer cells by the recombinant adenovirus p53. Proceedings for 86th American Association for Cancer Research 36: 437Abs2609; 1995.

151. Cirielli C, Pili R, Gloe TR, et al. Adenovirus-mediated gene transfer of wild-type p53 induces melanoma cell apoptosis in vitro and tumor growth inhibition in vivo. Proceedings for 86th American Association for Cancer Research 36: 421 Abs2508; 1995.

152. Fujiwara T, Cai DW, Georges RN, et al. Terapeutic effect of a retroviral wild- type p53 expression vector in an orthotopic lung cancer model. Journal of the National Cancer Institute 86: 1458-62; 1994.

153. Carbone DP, Minna JD. in vivo gene therapy of human lung cancer using wild-type p53 delivered by retrovirus. Journal of the National Cancer Institute 86: 1437-8; 1994.

154. Arteaga CL, Holt JT. Tissue-targeted antisense c-fos retroviral vector inhibits established breast cancer xenografts in nude mice. Cancer Research 56: 1098-103; 1996.

155. Clayman GL, el-Naggar AK, Roth JA, et al. In vivo molecular therapy with p53 adenovirus for microscopic residual head and neck squamous carcinoma. Cancer Research 55:1-6; 1995.

156. Kanjilal S, Strom SS, Clayman GL, et al. p53 mutations in nonmelanoma skin cancer of the head and neck: molecular evidence for field cancerization. Cancer Research 55:3604-9; 1995.

157. Carson DA, Lois A. Cancer progression and p53. Lancet 346: 1009-11; 1995. 
158. Mujoo K, Maneval DC, Anderson SC, et al. Adenoviral-mediated p53 tumor suppressor gene therapy of human ovarian carcinoma Adenoviral-mediated p53 tumor suppressor gene therapy of human ovarian carcinoma. Oncogene 12: 1617-23; 1996.

159. Yung WKA, Shi YX, Zhang WW, et al. Growth suppression of human glioma cells by restoration of wild-type p53 gene utilizing an adenovirus vector. Proceedings for 86th American Association for Cancer Research 36: 423Abs2524; 1995.

160. Cirielli C, Riccioni T, Yang C, et al. Adenovirus-mediated gene transfer of wild-type p53 results in melanoma cell apoptosis in vitro and in vivo. International Journal of Cancer 63: 673-9; 1995.

161. Zheng PS, Iwasaka T, Ouchida M, et al. Growth suppression of a cervical cancer cell line (tmcc-1) by the human wild-type p53 gene. Gynecologic Oncology 60: 245-50; 1996.

162. Seth P, Brinkmann U, Schwartz GN, et al. Adenovirus-mediated gene transfer to human breast tumor cells: An approach for cancer gene therapy and bone marrow purging. Cancer Research 56: 1346-51; 1996.

163. Liu TJ, el-Naggar AK, McDonnell TJ, et al. Apoptosis induction mediated by wild-type p53 adenoviral gene transfer in squamous cell carcinoma of the head and neck. Cancer Research 55: 3117-22; 1995.

164. Gomez-Manzano C, Fueyo J, Kyritsis AP, et al. Adenovirus-mediated transfer of the p53 gene produces rapid and generalized death of human glioma cells via apoptosis. Cancer Research 56: 694-9; 1996.

165. Schackert G, Frank S, Schackert HK. Gene therapy: Approaches for the treatment of malignant gliomas. Onkologie 19:16-22; 1996.

166. Gjerset RA, Turla ST, Sobol RE, et al. Use of wild-type p53 to achieve complete treatment sensitization of tumor cells expressing endogenous mutant p53. Molecular Carcinogenesis 14: 275-85; 1995.

167. Clayman GL, Liu TJ, Overholt SM, et al. Gene therapy for head and neck cancer. comparing the tumor suppressor gene p53 and a cell cycle regulator waf1/cip1 (p21). Archives of Otolaryngology - Head and Neck Surgery 122: 489-93; 1996.

168. Runnebaum IB, Kreienberg R. p53 trans-dominantly suppresses tumor formation of human breast cancer cells mediated by retroviral bulk infection without marker gene selection: an expeditious in vitro protocol with implications towards gene therapy. Hybridoma 14: 153-7; 1995.

169. Lesoon-Wood LA, Kim WH, Kleinman HK, et al. Systemic gene therapy with p53 reduces growth and metastases of a malignant human breast cancer in nude mice. Human Gene Therapy 6: 395-405; 1995.

170. Zhang WW, Alemany R, Wang J, et al. Safety evaluation of ad5cmv-p53 in vitro and in vivo. Human Gene Therapy: 155-64; 1995.

171. Da Costa LT, Jen J, He TC, et al. Converting cancer genes into killer genes. Proceedings of the National Academy of Science of the USA. 93:4192-6; 1996

172. Wills KN, Huang WM, Harris MP, et al. Gene therapy for hepatocellular carcinoma: chemosensitivity conferred by adenovirus-mediated transfer of the HSV-1 thymidine kinase gene. Cancer Gene Therapy 1995; 2: $191-7 ; 1995$.

173. Tanaka T, Kanai F, Okabe S, et al. Adenovirus-mediated prodrug gene therapy for carcinoembryonic antigen-producing human gastric carcinoma cells in vitro. Cancer Research 56: 1341-5; 1996. 
174. Kaneko S, Hallenbeck P, Kotani T, et al. Adenovirus-mediated gene therapy of hepatocellular carcinoma using cancer-specific gene expression. Cancer Research 55: 5283-7; 1995.

175. Vile R, Miller N, Chernajovsky Y, et al. A comparison of the properties of different retroviral vectors containing the murine tyrosinase promoter to achieve transcriptionally targeted expression of the HSVtk or IL-2 genes. Gene Therapy 1: 307-16; 1994.

176. Ido A, Nakata K, Kato Y, et al. Gene therapy for hepatoma cells using a retrovirus vector carrying herpes simplex virus thymidine kinase gene under the control of human alpha-fetoprotein gene promoter. Cancer Research 1995;55:3105-9.

\section{BIOGRAPHY}

Ming Yu, M.D., completed her medical studies at Beijing Medical University in 1982. She is presently a second-year graduate student pursuing a Ph.D. degree at Georgetown University (Washington, DC, USA).

Copyright (C) 1996 by MJM 